22. Prlz, W., Z. analyt. Chem. 193, 338 (1963). - 23. Pruz, W. und I. Johann, Z. analyt. Chem. 218, 426 (1966). - 24. Pruz, W., I. JohanN und E. Stelzi, Klin. Wschr. 43, 1227 (1965). - 25. Pilz, W. und I. JohanN, Z. analyt. Chem. 215, 105 (1965). -
26. Pruz, W., Hoppe-Seyler's Z. physiol. Chem. 328, 247 (1962). 27. PrLz, W. und H. HörLen, Hoppe-Seyler's Z. physiol. Chem. 330, 212 (1963). - 28. Priz, W. und E. Stezzz in Vorbereitung.
Dr. W. Pilz

Physiol.-chem. u. analyt. Labor der ärztl. Abt. 509 Leverkusen-Bayerwerk

\title{
Chlorid-Bestimmungen in nativem Humanserum mit Filter-Flammenphotometern
}

\author{
Von G. Bechtler, B. Gutsche, R. Herrmann, W. Lang und D. Stamm¹)
}

\begin{abstract}
Aus der Ampendungstecbnischen Abteilung der Firma Eppendorf Gerätebau, Hamburg, der Abteilung für Medizinische Physite an der Universitäts-Hauttlinik Gießen und der Abteilung für Klinische Chemie des Max-Planck-Institutes für Psychiatrie, München
\end{abstract}

(Eingegangen am 20. Januar 1967)

Es werden zwei nur wenig verschiedene Methoden zur Serum-Chlorid-Bestimmung in nativem Humanserum angegeben, die für zwei verschiedene, handelsübliche Typen von Filterflammenphotometern ausgearbeitet wurden. Damit kann man mit solchen einfachen Ge_ räten nicht nur Natrium, Kalium und Calcium, sondern zusätzlich auch noch Chlor bestimmen. Es wird gezeigt, daß die Genauigkei und Richtigkeit der Methode ausgezeichnet ist, gleichgültig, welche der beiden Methoden und welches der beiden Geräte man verwendet.

Two methods are given for the measurement of chloride in native human serum; they differ only slightly, depending on which of two commercial filter-flame photometers is used. Thus, with these simple apparatuses, not only sodium, potassium and calcium, but also chlorine can be measured. The accuracy and precision of the method are very good, and are the same for both methods and both machines.

In zwei vorangegangenen Arbeiten $(1,2)$ war gezeigt worden, daß man mit Hilfe von Flammen-Spektralphotometern den Chlorid-Gehalt in nativem Humanserum mit außerordentlich geringer Streubreite (Synonyma: Präzision, Reproduzierbarkeit; charakterisiert durch die Standardabweichung) bestimmen kann. Die erzielbaren Genauigkeiten dieser indirekten Methode übertreffen sogar die der üblichen direkten flammenphotometrischen Methode. Außerdem war gezeigt worden, daß die vorgeschlagene Methode auch mit sehr guter Richtigkeit arbeitet.

Für die Durchführung dieser früheren Untersuchungen wurde ein aus handelsüblichen Bauteilen zusammengestelltes Flammenphotometer verwendet, bei dem die interessierende Strahlung mit einem Monocbromator aus dem Spektrum der Flamme ausgesondert wurde. Üblicherweise werden jedoch für flammenphotometrische Analysen im klinischen Labor Flammenphotometer mit Filtern - an Stelle eines Monochromators - ausgerüstet. In der vorliegenden Arbeit soll daher gezeigt werden, daß auch mit handelsüblichen Filter-Flammenphotometern (unter Umständen nach Austausch einiger Bauteile) Serum-Chlorid-Analysen möglich sind, sofern man die Methode auf das jeweilige Gerät richtig anpaßt. Die Untersuchungen erfolgten mit dem Flammenphotometer der Fa. Eppendorf Gerätebau, und mit dem Filterflammenphotometer PF 5 der Fa. Carl Zeiss, Oberkochen. Es soll im folgenden über beide methodische Entwicklungen berichtet werden; die Vor- und Nachteile beider Methoden werden einander gegenübergestellt.

\footnotetext{
1) Die methodischen Untersuchungen der Abteilung für Medizinische Physik in Gießen wurden mit Mitteln der Deutschen Forschungsgemeinschaft unterstützt.
}

\section{Apparative Einrichtungen}

Flammenphotometer Eppendorf in der standardmäßigen Ausführung. Zusätzlich werden der Brenner für Wasserstoff/Acetylen, das Flaschenventil für Wasserstoff mit Druckminderer und Zuleitungsschlauch sowie ein Filter zur Silberbestimmung (Schott, UV-Depil $338 \mathrm{~m} \mu$ ) benötigt. Das in diesem Fall verwendete Filter hatte nach zusätzlicher Verkittung mit $3 \mathrm{~mm}$ UG 3 eine Maximaldurchlässigkeit von $28,8 \%$ bei $337 \mathrm{~m} \mu$, seine Halbwertsbreite betrug $\pm 5,7 \mathrm{~m} \mu$ und die Zehntel-Wertsbreite $\pm 10,7 \mathrm{~m} \mu$. Das Silberfilter wird in eine der Leerstellen der Filtertrommel eingesetzt, der Propan/AcetylenBrenner gegen den Wasserstoff/Acetylen-Brenner ausgetauscht, wobei zusätzlich die Düse $0,5 \mathrm{~mm} \varnothing$ aus der Brenngasleitung vor dem Brenner ausgeschraubt werden muß (3). Die Propanzuleitung wird am Gerät abgeschraubt und durch die Wasserstoffleitung ersetzt. Sollen außerdem $\mathrm{Na}, \mathrm{K}$ und $\mathrm{Ca}$ bestimmt werden, so wird das Gerät für die beiden Alkalimetalle mit Wasserstoff, für das Erdalkalielement mit Acetylen als Brenngas betrieben. Gerät PF 5 der Fa. Carl Zeiss, Oberkochen. Falls ungenügende UV-Empfindlichkeit bei $338 \mathrm{~m} \mu$ vorhanden sein sollte, empfiehlt sich folgendes:

Strahlungsempfänger 1 P 22 ersetzen durch 1 P 28, beide von der Fa. „R̈adio-Corporation of America“ erhältlich. Wenn man ausgesuchte Exemplare von 1 P 22 verwendet, ist dieser Austausch nicht erforderlich. Wenn man solche Exemplare von $1 \mathrm{P} 28$ verwendet, die auch im langwelligen Bereich noch genügend Empfindlichkeit haben ${ }^{2}$ ), kann man den gleichen 1 P 28 für Na-, K-, Ca- und $\mathrm{Cl}$-Analysen verwenden. Das gleiche gilt naturgemäß auch für entsprechend ausgesuchte Exemplare von 1 P 22.

Glaskondensor ersetzen durch einen besser UV-durchlässigen Kondensor ${ }^{3}$ ). Wenn man gut ausgesuchte 1 P 28 bzw. 1 P 22

2) z. B. 2 CA 128a oder HTV 213.

3) Der Fa. Carl Zeiss, Oberkochen, danken wir für die freundliche Úberlassung eines Quarzkondensators. 


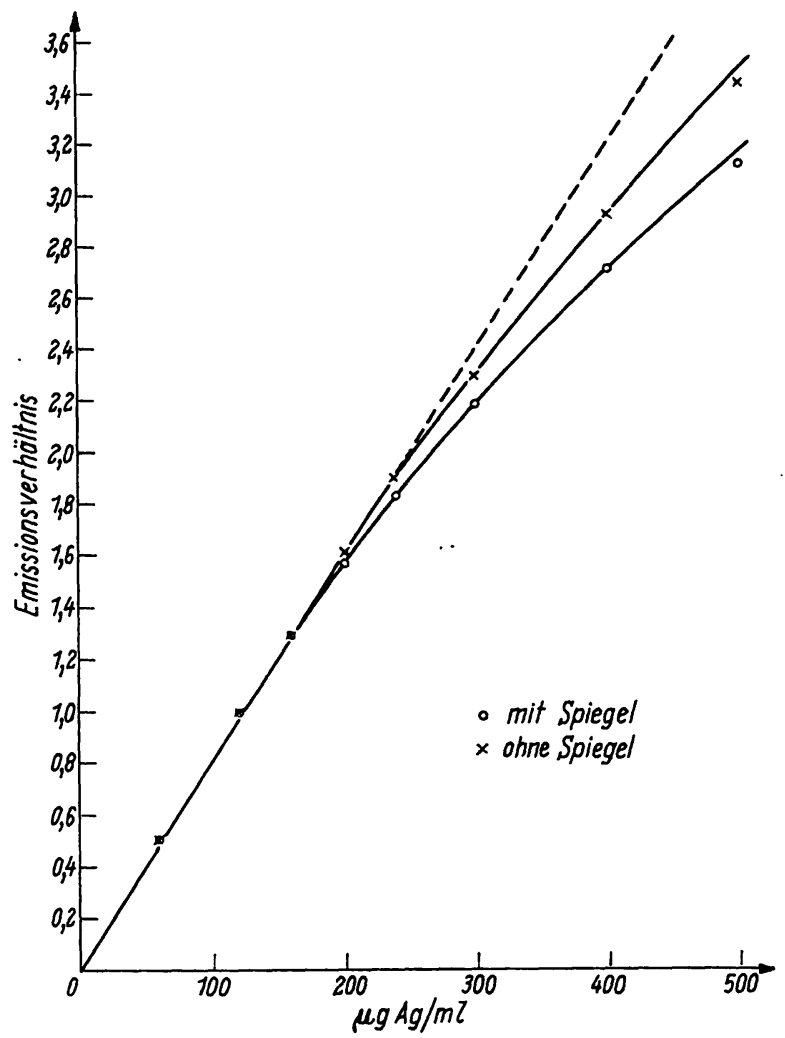

Abb. 1

Ag-Eichkurve für wäßrige Silberlösungen mit einem konstanten $\mathrm{Na}-G$ ehalt von $10,65 \mathrm{mg} \mathrm{Na} / 100 \mathrm{~m} /$ gemessen mit dem PF 5 mit dem im Text genannten Filter für $\mathrm{Ag} 338,3 \mathrm{~m} \mu$.

a) mit Rückspiegel, b) ohne Rückspiegel

hoher Empfindlichkeit bei $338 \mathrm{~m} \mu$ hat, dann kann man bei stärkerer Empfindlichkeitseinstellung (höherer Nachverstärkung) auch mit dem normalerweise eingebauten Glaskondensor auskommen.

Die Acetylen-Gasdüse aufbohren auf $0,7 \mathrm{~mm}$. Die gleiche Düse ist dann nach wie vor noch für Acetylen brauchbar, man muß dann nur nach dem Aufbohren mit dem Druck am Manometer beim Arbeiten mit Acetylen etwas heruntergehen, bei unserem Gerät von $150 \mathrm{~mm}$ WS auf $90 \mathrm{~mm}$ WS.

Die normale Acetylenbrennerkappe ersetzen durch eine gleiche Kappe, bei der die zwei inneren konzentrischen engeren Lochreihen mit Metalldrähten verschlossen $\operatorname{sind}^{1}$ ).

Falls die Eichkurve bis herauf $\mathrm{zu} 150 \mu \mathrm{g} \mathrm{Ag} / \mathrm{ml}$ nicht genügend geradlinig ist, kann man eine zusätzliche Linearisierung der Eichkurve erreichen, indem man den Rückspiegel herausschraubt (s. Abb. 1). Bei unserem Gerät war das nicht erforderlich. Im übrigen lassen sich bei entsprechend höheren Nachverstärkungen auch $\mathrm{Na}-\mathrm{K}$ - und Ca-Analysen im Serum ohne Rückspiegel ausführen.

Das Photometer ist bei Cl-Analysen statt mit Acetylen mit Wasserstoff zu betreiben. Das gleiche $\mathrm{Gas}$ ist auch für $\mathrm{Na}$ - und K-Analysen brauchbar. Unter Umständen kann man die Ca-Analysẹn-Methode so abändern, daß diese auch mit der Wasserstoff-Preßluftflamme ausführbar ist. Diesbezügliche Untersuchungen haben wir noch nicht durchgeführt. Die eingebauten Druckminderventile bleiben die gleichen wie bei Acetylen-Preßluft.

Am Filterwechselrevolver ist anstelle eines Ieerfilters ein UVInterferenz-Doppellinienfilter der Fa. Schott für die Silberlinie $338,29 \mathrm{~m} \mu$ anzubringen. Das verwendete Filter hatte folgende Eigenschaften: Maximaldurchlässigkeit bei $338,5 \mathrm{~m} \mu$; Maximaldurchlässigkeit $36,5 \%$; Halbwertsbreite $\pm 4,4 \mathrm{~m} \mu$; ZehntelWertsbreite $\pm 11,5 \mathrm{~m} \mu$.

1) Herrn Dr. H. Prugger, Oberkochen, danken wir für diesen Hinweis.
Um die Kunststoffreaktionsgefäße mit Deckel aus dem Mikrolitersystem „Eppendorf" (Hersteller Fa. Eppendorf Gerätebau, Hamburg) bequem unter die Ansaugkapillare halten zu können, haben wir den Probenwechseltisch am PF 5 abgeschraubt.

\section{Optimale Betriebsbedingungen}

Als optimaler Gasdruck erwies sich beim Gerät Eppendorf $900 \mathrm{~mm}$ Wassersäule für Wasserstoff und 0,5 atü für Luft. Beim PF 5 wurden die Betriebsbedingungen so gewählt, daß ein optimales Linien/Untergrund-Verhältnis entstand. Zu diesem Zweck wurde der Preßluftdruck auf dem Normaldruck von $1,0 \mathrm{kp} / \mathrm{cm}^{2}$ konstant gehalten und der Wasserstoffdruck variiert. Es zeigt sich, $\mathrm{da}$ das Linien/Untergrund-Verhältnis relativ wenig vom eingestellten Mischungsverhältnis abhängt. Wir wählten den höchst möglichen Wasserstoffdruck den das Meßinstrument am PF 5 anzeigt, nämlich $250 \mathrm{~mm}$ WS.

\section{Untere Nachweisgrenze des Silbers}

Es wurde je eine salpetersaure Blindlösung $(0,5 \mathrm{~N})$ hergestellt, welche zusätzlich $58 \mathrm{mg} \mathrm{NaNO}_{3} / 100 \mathrm{~m} /$ (für Gerät Eppendorf) bzw. $39,7 \mathrm{mg} \mathrm{NaNO} / 100 \mathrm{ml}$ (für Gerät Zeiss) enthielt. Die Natriumkonzentration dieser Lösungen entspricht im ersten Falle einem 1:21 und im zweiten Falle einem 1:31 verdünnten Serum.

Die Standardlösung (Eichlösung) wies den gleichen Natrium- und Salpetersäuregehalt auf, enthielt aber zusätzlich noch Silbernitrat, und zwar $1,575 \mathrm{mg} \mathrm{AgNO}_{3} /$ $100 \mathrm{ml}$ entsprechend $1,0 \mathrm{mg} \mathrm{Ag} / 100 \mathrm{ml}$ für Gerät Eppendorf und 0,788 $\mathrm{mg} \mathrm{AgNO}_{3} / 100 \mathrm{ml}$ entsprechend $0,5 \mathrm{mg} \mathrm{Ag} / 100 \mathrm{ml}$ für Gerät PF 5. Beide Lösungen wurden nun im Wechsel gegen dest. Wasser als Nulllösung (beim PF 5 gegen abgedunkelten Strahlungsempfänger) jeweils $20 \mathrm{mal}$ zerstäubt und die erhaltenen Meßwerte benutzt, um die untere Nachweisgrenze (4) zu ermitteln:

$$
\mathrm{x}_{\mathrm{A}}-\mathrm{x}_{\mathrm{A}, \mathrm{bl}} \geq 3 \sqrt{2} \sigma_{\mathrm{bl}}
$$

$\mathrm{x}_{\mathbf{A}}=$ Meßwert in der Nähe der Nachweisgrenze, $\mathrm{x}_{\mathrm{A}, \mathrm{bl}}=$ Bezugswert, $\sigma_{\mathrm{bl}}=$ Standardabweichung des Blindwertes. Als Nachweisgrenze errechnete sich daraus für beide Geräte $0,3 \mathrm{mg} \mathrm{Ag} / 100 \mathrm{~m} /$.

Diese Silberkonzentration entspricht bei Verwendung der bier angegebenen Methode für das Gerät Eppendorf einer Chlorkonzentration von $0,30 \mathrm{mVal}$ Chlor und bei Verwendung der hier für das Gerät PF 5 von Zeiss angegebenen Methode einer Konzentration von $0,15 \mathrm{mVal}$ Chlor. Selbstverständlich ändern sich diese Relationen Silbernachweisgrenze $\mathrm{zu}$ Chlornachweisgrenze für beide Geräte, wenn man methodische Variationen vornimmt $(1,2,6)$.

\section{Silber-Eichkurve}

Zur Bestimmung der Eichkurve für das PF 5 wurden Lösungen konstanten Na-Gehaltes (10,65 mg Na/ $100 \mathrm{~m} l$ ) und steigender Ag-Konzentrationen ( 0 bis $20 \mathrm{mg} \mathrm{Ag} / 100 \mathrm{~m} l$ ) hergestellt und die jeweiligen Ausschläge im Vergleich zu einer mittleren Ag-Konzentration von $12 \mathrm{mg} \mathrm{Ag} / 100 \mathrm{~m} / \mathrm{nach}$ dem Quotienten-Verfahren (5) ermittelt. Mit diesen Werten wurde die Eichkurve gezeichnet (Abb. 1). Es zeigt sich beim PF 5, daß $\mathrm{im}$ Konzentrationsbereich von $0-18 \mathrm{mg} \mathrm{Ag} / 100 \mathrm{~m} l$ die Eichkurve der Silberbestimmung geradlinig verläuft. 
Beim Eppendorf-Gerät ergaben entsprechende Untersuchungen einen Linearitätsbereich von $0-65 \mathrm{mg}$ $\mathrm{Ag} / 100 \mathrm{~m} /$. Der Unterschied dürfte durch die verschiedene Tröpfchenaussonderung in den Zerstäuberkammern der beiden Geräte bedingt sein.

\section{Methodik \\ Apparatur}

Für die Bestimmung am Eppendorf-Gerät werden aus dem Mikrolitersystem „Eppendorf“ ein Arbeitsblock mit Wechselaufsatz, der Rotationsmischer, die Zentrifuge, je eine $50 \mu l$ und $1000 \mu l$ Marburg-Pipette mit den zugehörigen Spitzen und Reaktionsgefäßen benötigt.

Für die Bestimmung am $P F 5$ werden die gleichen Hilfsmittel benutzt. Lediglich die $1000 \mu l$ Marlurg-Pipette wird durch eine $1,5 \mathrm{ml}$ Vollpipette ersetzt. Eine Reinigung der Reaktionsgefäße und Spitzen entfällt, da sie nach einmaligem Gebrauch verworfen werden.

\section{Reagenzien}

Für beide Methoden: Silbernitrat p. a. (Fa. Merck, Nr. 1512); Natriumnitrat p. a. (Fa. Merck, Nr. 6537); Salpetersäure 65\% p. a. (Fa. Merck, Nr. 454); Natriumchlorid p. a. (Fa. Merck, Nr. 6404). (Nur zur Eichung beim Eppendorf-Gerät notwendig.)

\section{Lösungen}

1N Salpetersäure (für beide Methoden): $69 \mathrm{ml}$ 65-proz. Salpetersäure werden mit bidest. Wasser auf $1000 \mathrm{ml}$ aufgefüllt.

Fällungsreagenz (Die Zahlenangaben in Klammern beziehen sich auf die angegebene Methode am $P F 5$ ).

$1023 \mathrm{mg}$ (682 mg) Silbernitrat werden in $500 \mathrm{~m} / 1 \mathrm{~N}$ Salpetersäure gelöst. Anschließend wird mit bidest. Wasser auf $1000 \mathrm{ml}$ aufgefüllt.

\section{Standardlösung}

$244 \mathrm{mg}(94,5 \mathrm{mg})$ Silbernitrat und $580 \mathrm{mg}(397 \mathrm{mg})$ Natriumnitrat werden in $500 \mathrm{~m} l 1 \mathrm{~N}$ Salpetersäure gelöst und mit bidest. Wasser auf $1000 \mathrm{~m} l$ aufgefüllt.

\section{Blindlösung}

$580 \mathrm{mg}$ (397 mg) Natriumnitrat werden in $500 \mathrm{ml}$ 1N Salpetersäure gelöst und mit bidest. Wasser auf $1000 \mathrm{ml}$ aufgefüllt.

Vorbereitung der Seren

Metbode zum Gerät Eppendorf

Man pipettiert in Reaktionsgefäße $50 \mu l$ Serum, $1000 \mu l$ Fällungsreagenz, rüttelt die verschlossenen Gefäße etwa 1 Min. auf dem Rotationsmischer, läßt sie 1-2 Min. stehen und zentrifugiett anschließend 2 Min. bei etwa $15000 \mathrm{~g}$ in der Mikrozentrifuge. Der Uberstand wird ohne Dekantieren gemessen, wobei darauf geachtet werden soll, daß der Ansaugrüssel des Flammenphotometers den Niederschlag nicht aufwirbelt. Als Skala benutzt man die in mVal kalibrierte Natriumskala. Man saugt zuerst Blindlösung an, kompensiert auf 0 , anschließend wird mit der Standardlösung, die $90 \mathrm{mVal}$ Chlorid im Serum entspricht, die Lichtmarke auf 100 gebracht. Mit dieser Einstellung, die wie üblich zwischenzeitlich kontrolliert wird, bestimmt man die Emission der Serumproben.

Pathologische Seren, deren Chloridgehalt über $120 \mathrm{mVal}$ liegt, werden nicht richtig bestimmt, wie weiter unten exläutert wird. Um diese Schwierigkeiten zu umgehen, gibt es mehrere Möglichkeiten. Die erste besteht darin, alle Seren, deren Gehalt über 115 $\mathrm{mVal}$ Chlorid liegen, 1:2 mit Blindlösung vorzuverdünnen. Die erhaltenen Werte müssen dann nach der Berechnung mit dem Faktor 2 multipliziert werden. Nach den vorliegenden Ergebnissen können auf diese Weise Chloridkonzentrationen bis $160 \mathrm{mVal}$ noch erfaßt werden. Die zweite Möglichkeit extreme Werte zu erkennen, ist die später beschriebene Tüpfelreaktion. Die letzte besteht darin, alle Seren im Doppelansatz (unverdünnt und 1:2 mit Blindlösung vorverdünnt) zu messen. Näher wird diese Methode weiter unten beschrieben.

\section{Methode zum Gerät PF 5}

$50 \mu l$ frisches Serum und $1,5 \mathrm{~m} l$ Fällungsreagenz in cin Reaktionsgefäß pipettieren, mit einem Platindraht umrühren, 2 Min. in der Mikrozentrifuge zentrifugieren und anschließend unmittelbar aus dem Reaktionsgefä $\beta$ die Probe in die Flamme zerstäuben. Der Platindraht ist empfehlenswert, da Platin bei der Fällung als Katalysator wirkt und die Ausflockung begünstigt (6). Während der Zerstäubung der Probenlösung ist darauf zu achten, daß die Ansaugkapillare nicht in den Silberchlorid-Niederschlag kommt. Gemessen wurde am PF 5 zunächst mit einer linearen, von 0-100 geteilten Skala bei der Ag-Linie 338,3 m $\mu$. Es werden die jeweiligen Skalenteile abgelesen und in die unten genannten Gleichungen eingesetzt. Empfindlichkeits-Einstellung etwa Stufe 7, Kompensation des Flammenuntergrundes beim Zerstäuben der Blindlösung zu 0. Bei Aufbewahrung im Dunkeln können die so vorbereiteten Proben einige Stdn. stehen. Um Chlorid-Werte über $120 \mathrm{mVal}$ messen zu können, schlagen wir bei einer Chloridanzeige über $115 \mathrm{mVal}$ eine Vorverdünnung des Serums $1+0,2(50 \mu l$ Serum $+10 \mu l$ Blindlösung) vor (s. unten).

\section{Reihenfolge der Messungen}

Methode zum Gerät Eppendorf

Werden nur die über $115 \mathrm{mVal}$ liegenden Seren verdünnt, so ist nur das oben Gesagte zu berücksichtigen.

Bei genereller Verdünnung aller Seren, geht man wie folgt vor: $\mathrm{Zu}$ nächst werden die mit Blindlösung verdünnten Seren zerstäubt, selbstverständlich nachdem Blind- und Eichwert entsprechend eingeregelt sind. In den meisten Fällen (mehr als $99 \%$ ) werden hier Werte nicht ablesbar sein (Anzeige unter $60 \mathrm{mVal}$ Chlorid bzw. bei Einstellung der Standardlösung auf 100 Skalenteile der Natriumskala, Serumwerte über 180 Skalenteile). Das ist dann jeweils ein Zeichen dafür, daß bei diesen Seren die Chlorkonzentration im Normalbereich liegt. Es interessiert dann nur die Emission der nicht mit Blindlösung verdünnten Seren, die anschließend gemessen werden. Ist aber ausnahmsweise ein mit aqua dest. verdünntes Serum ablesbar, dann ist dieser abgelesene Wert, wie unten ausgeführt, zu berechnen, und wegen der Vorverdünnung mit 2 zu multiplizieren.

\section{Metboden zum Gerät PF 5 von Zeiss}

Werden die über $115 \mathrm{mVal}$ liegenden Seren verdünnt, ist nur das oben Gesagte zu berücksichtigen.

Bei genereller Verdünnung aller Seren geht man wie folgt vor: Hier werden $1+0,2$ mit Blindlösung verdünnte Seren $(50 \mu l$ Serum + $10 \mu l$ Blindlösung) auch wieder zuerst zerstäubt, selbstverständlich wieder nach entsprechender Einregelung von Blind- und Eichwert (s. o.). Es brauchen hier in dieser Reihe nur solche Werte abgelesen zu werden, die ausnahmsweise Anzeigen oberhalb 100 $\mathrm{mVal}$ ergeben. Diese abgelesenen Werte sind nachher wegen der Vorverdünnung mit 1,2 zu multiplizieren. Alle übrigen Seren (mehr als $99 \%$ aller Fälle) dieser stärker verdünnten Reihe werden Werte unterhalb $100 \mathrm{mVal}$ Chlor ergeben. Diese wird man zweckmäßigerweise gar nicht ablesen. Man mißt dann anschließend die nicht verdünnte Reihe, wobei die Skalenwerte sofort die gesuchten $\mathrm{mVal}$ Chlor ergeben, ohne daß man nachträglich multiplizieren muß.

\section{Auswertung der Meßergebnisse}

Die Serum-Chlorid-Konzentration ist mit folgender Gleichung zu ermitteln, sofern man nicht in Konzentrationseinheiten geeichte Skalen verwendet $(s . u)$ :

\section{Eppendorf-Gerät}

$$
120-30 \frac{I_{\text {Serum }}}{I_{\text {Standard }}}=\mathrm{mVal} \text { Chlorid }
$$

Da die Emission des Standard ( I $_{\text {Standard }}$ ) auf 100 Skalenteile eingestellt wird, vereinfacht sich die Berechnung zu:

$$
120-0,3 \cdot \text { I }_{\text {Serum }}=\mathrm{mVal} \text { Chlorid. }
$$

\section{PF 5-Gerät}

$$
C_{s}=4277-613,8 \frac{\mathrm{Ix}}{\mathrm{I}_{\mathrm{E}}}\left(\mathrm{C}_{\mathrm{s}} \text { in } \mu \mathrm{g} \mathrm{Cl} / \mathrm{ml}\right),
$$


oder falls in $\mathrm{mVal}$ gewünscht:

$$
\mathrm{C}_{\mathrm{s}}=120,4-17,3 \frac{\mathrm{Ix}}{\mathrm{I}_{\mathrm{E}}}
$$

Die Ableitung dieser Gleichung ist in (1) gegeben.

Diese letzten Beziehungen kann man auch in Form einer fertigen Skala zeichnen und anstelle der vorhandenen Skala in das Gerät einschieben, so daß man den Chlor-Gehalt direkt ablesen kann. Die Abbildung 2 zeigt solche Skalen, von denen die eine in $\mathrm{mVal} / \mathrm{l}$, die andere in $\mathrm{mg} / 1000 \mathrm{ml}$ geteilt ist.

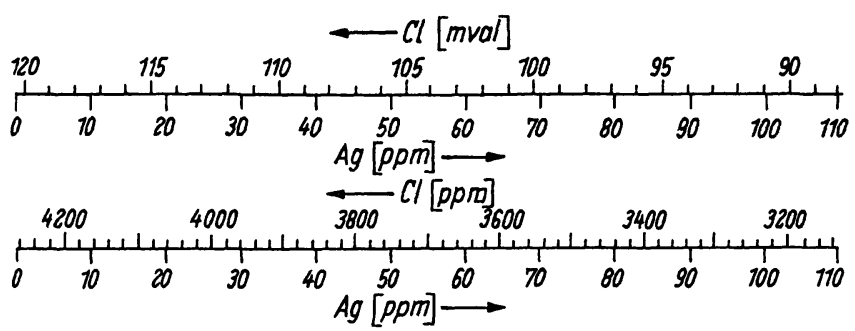

Abb. 2

- Das Aussehen zweier in Chlor-Konzentration (unten in $\mathrm{mg} \mathrm{Cl}$ / $1000 \mathrm{ml}$, oben in mVal) geeichten Skalen, die man in das PF 5 einschieben kann

\section{Prüfung der Methode}

\section{Einfluß der Lösungspartner}

Bei beiden Methoden stellt man einen kleinen Störeinfluß von Natrium auf die Silber-Anzeige fest. Bei den eingangs zitierten $z$ wei Methoden mit Monochromator $(1,2)$ kam ein solcher Störeinfluß wegen der benutzten geringeren Bandbreite nicht heraus. Die Größe dieses im übrigen leicht zu behebenden Störeinflusses kommt bei beiden Filter-Geräten etwas verschieden heraus, weil verschiedene Verdünnungen angewandt wurden und weil die Flammentemperatur verschieden gewesen sein dürfte.

Ein Störeinfluß der Salpetersäure ist bei stärker geänderten Normalitäten zu beobachten. Wir haben diesen Störeinflu $ß$ dadurch beseitigt, da $\beta$ wir alle Lösungen $0,5 \mathrm{~N}$ salpetersauer gemacht haben. - Ein Störeinfluß von Phosphor wurde in allen Fällen nicht festgestellt.

\section{Störeinfluß von Natrium}

\section{Metbode zum Eppendorf-Gerät}

Die Untersuchungen der Na-Störungen ergaben, daß die Beeinflussung der Emission der Standardlösung etwa 1\% pro $10 \mathrm{mVal}$ Natrium beträgt, auf Chlorid bezogen also etwa $0,25 \%$ pro $10 \mathrm{mVal}$ Natrium. Deshalb kann eine Korrektur unterschiedlicher Natriumgehalte verschiedener Seren entfallen. Es genügt, wenn Blind- und Eichlösung generell eine $143 \mathrm{mVal}$ Natrium im Serum entsprechende $\mathrm{Na}-\mathrm{Konzentration}$ aufweisen.

\section{Metbode zum PF 5-Gerät}

Es wurden Lösungen mit konstantem Silbergehalt aber variierten Elektrolytkonzentrationen hergestellt. Ess zeigt sich dabei, wie oben, daß lediglich der relativ hohe Na-Gehalt des Serums in den Eichlösungen zu berücksichtigen ist, da nut dieses Element aus dem gleichen Grunde einen geringen Einfluß auf die Ag-Anzeige hat. Das Beseitigen dieser Störung erfolgt entsprechend durch Hineinnehmen des mittleren Serum-Na-Gehaltes in alle Lösungen.

\section{Bestimmung der Genauigkeit}

Methode zum Eppendorf-Gerät

Die Genauigkeit der Methode wurde sowohl unter Verwendung von Marburg-Pipetten wie auch unter Benutzung einer Verdünnungseinrichtung bestimmt. Dieses Verdünnungsgerät, welches zur Erweiterung des Mikrolitersystems „Eppendorf“ dient, soll an anderer Stelle beschrieben werden. Um in etwa der Praxis entsprechende Verhältnisse $z u$ bekommen, wurden 50 flammenphotometrische Serum-Cl-Bestimmungen an 2 bzw. 3 Tagen vorgenommen, wobei zu beachten ist, da $ß$ für die Marburg-Pipetten und das Verdünnungsgerät $z$ wei verschiedene Seren verwendet wurden. Es sind im folgenden die Mittelwerte $\overline{\mathbf{x}}$, die Streuungen $s$ und die Variationskoeffizienten $\mathrm{v}$ angegeben.

\begin{tabular}{ll}
\hline Narburg-Pipetten & Verdünnungsgerät \\
\hline$\overline{\mathbf{x}}=103,9 \mathrm{mVal}$ & $\overline{\mathrm{x}}=105,5 \mathrm{mVal}$ \\
$\mathrm{s}=0,7 \mathrm{mVal}$ & $\mathrm{s}=0,45 \mathrm{mVal}$ \\
$\mathbf{v}=0,67 \%$ & $\mathrm{v}=0,43 \%$ \\
\hline
\end{tabular}

Die Streubreiten sind sehr gering, d. h. die Präzision (Genauigkeit) ist sehr gut und genügt auch in etwa den Vorschriften des "College of American Pathologists", wonach die Standardabweichung einer Methode $1 / 16$ des Normbereiches, in diesem Falle 0,6 mVal, nicht wesentlich überschreiten soll.

\section{Metbode zum PF 5-Gerät}

Es wurde eine größere Menge Mischserum vorbereitet und $25 \mathrm{mal}$ nacheinander gegen Eich- und Blindlösung gemessen, die Skalenteile notiert und bei jedem Meßwert für sich die Chlorkonzentration errechnet. Von diesen Ergebnissen wurde in der üblichen Art die Standardabweichung errechnet. Sie ergab sich $z u \pm 0,4 \%$.

\section{Überpriifung der Ricbtigkeit \\ Metbode qum Eppendorf-Gerät}

Die Richtigkeit der Methode wurde auf verschiedene Weise geprüft:

Zuerst wurde die Richtigkeit wäßriger, salpetersaurer Lösungen untersucht. Zu diesem Zweck wurden eine Reihe von Standardlösungen im Bereich von 20 bis 120 mVal Chlorid durch Einwage von trockenem Natriumchlorid erstellt, wobei die Summe des Natriums durch Zugabe von Natriumnitrat auf $140 \mathrm{mVal}$ gehalten wurde. Diese Standardlösungen wurden im Flammenphotometer zerstäubt und die berechneten Werte zur Aufstellung einer Regressionsgeraden benutzt. Ihre Gleichung lautet: $y=-0,2+1,003 x$. Der ermittelte Korrelations-Koeffizient beträgt $r=0,999$. Diese Daten zeigen, daß das vorgegebene Chlorid in wäßriger, salpetersaurer Lösung gut wiedergefunden wird.

Die Richtigkeit der Serumwerte prüften wir zuerst durch Bestimmung des bekannten Gehaltes käuflicher Standardseren nach der vorliegenden Methode. Die erhaltenen Werte sind in Tabelle 1 aufgeführt. 
Tab. 1

\begin{tabular}{lcc}
\hline & \multicolumn{2}{c}{ mVal Chlorid } \\
Standardseren $\left.{ }^{2}\right)$ & gegeben & gefunden \\
\hline Moni-trol I & 103,1 & 102 \\
Moni-trol II & 83,4 & 86 \\
Lab-trol & 102,4 & 103 \\
Patho-trol & 111,8 & 113 \\
Versa-trol & 100,1 & 101 \\
Versa-trol Pediatric & 101,5 & 105 \\
\hline
\end{tabular}

1) Hersteller: Dade Reagents, Inc. Miami-Florida; in Deutschland zu beziehen durch: Asid-Institut GMBH. München-Lohhof.

Anschließend untersuchten wir 16 frische Humanseren sowohl merkurimetrisch $(8,9)$ mit dem „Merckotest ${ }^{\left({ }^{(1}\right.}$ ) als auch nach der beschriebenen flammenphotometrischen Methode. Die Wertepaare der unbekannten Seren wurden statistisch untersucht, wobei der Mittelwertsunterschied 0,6 und der Erwartungswert der Streuung $1,4 \%$ betrug.

\section{Methode zum PF 5-Gerät}

Zur Prüfung der Richtigkeit wurde der Erwartungswert der Streuung $\mathrm{E}(\mathrm{Str})$ nach der von (10) angegebenen Methode nach der Beziehung ermittelt:

$$
\mathrm{E}(\mathrm{Str})=\sqrt{\frac{\Sigma(\Delta)^{2}}{2 \mathrm{~m}}}
$$

Es bedeuten $\Delta$ die Abweichungen der Ergebnisse, $\mathrm{m}$ die Zahl der Doppelbestimmungen.

Aus 30 Doppelbestimmungen mit der angegebenen flammenphotometrischen Methode einerseits und der von STAMM angegebenen potentiometrischen Methode (11) andererseits ergibt sich ein $\mathrm{E}(\mathrm{Str})=0,771 \mathrm{mVal} \mathrm{Cl}$, oder von $0,73 \%$. Außerdem wurde für das gleiche Kollektiv die Regressionsgerade berechnet. Wir erhalten: $\mathrm{y}=0,08+1,01 \mathrm{x}$.

Fehler beim Überschreiten des Meßbereiches Die Methode der flammenphotometrischen Chloridanalyse hat zur Voraussetzung, da $\beta$ das Chlorid der Serumprobe durch Zugabe einer bekannten Menge Silbernitrat im Überschuß vollständig als AgCl-Niederschlag ausfällt. Nur dann ist die flammenphotometrisch bestimmte Konzentration des restlichen Silbers in der überstehenden Lösung ein Maß für die Chloridkonzentration. Hieraus folgt, daß bei einer gegebenen Analysenvorschrift Chloridkonzentrationen nur bis zu einer gewissen oberen Grenze analysiert werden können. Diese obere Grenze liegt dann vor, wenn für die Chloridfällung das zugesetzte Silber restlos verbraucht wird, der Silberüberschuß also fehlt. Übersteigt die zu messende Chloridkonzentration die genannte obere Grenze, so muß man entweder die Chloridprobe entsprechend verdünnen oder aber die als Fällungsreagenz zugesetzte Silbermenge erhöhen. Im letztgenannten Falle darf jedoch der Silberüberschuß aus Genauigkeitsgründen nicht zu groß gewählt werden, worauf an anderen Stellen (1) ausführlich eingegangen wird.

Mit den beiden beschriebenen Methoden für das Eppendorf- bzw. für das Zeiss-Gerät können Serumchlorid-

1) Hersteller: Fa. E. Merck AG., Darmstadt. konzentrationen bis herauf $\mathrm{zu} 120 \mathrm{mVal}$ (4277 $\mu \mathrm{g}$ $\mathrm{Cl} / \mathrm{m} l)$ bestimmt werden. Erfahrungsgemä $\beta$ liegt bei mehr als $99 \%$ aller Fälle die Chloridkonzentration im Humanserum unter diesem Wert. Wenn aber ausnahmsweise bei einem pathologischen Serum der Chloridgehalt $120 \mathrm{mVal}$ übersteigt, dann müßte die Silberkonzentration im Überstand unter Beibehaltung der o. a. Methode 0 sein. d. h. der Ausschlag am Flammenphotometer müßte dem Blindwert gleich sein. Tatsächlich tritt aber folgende Komplikation ein: $\mathrm{Zu}$ hohe Chlorkonzentrationen wirken stabilisierend auf das bei der Fällung neben dem käsigen Niederschlag gebildete kolloidale Silberchlorid, welches die Lösung über dem Niederschlag trübe erscheinen läßt (12). Dieses im Überstand befindliche kolloidale Silber wird aber vom Flammenphotometer gemessen: Die endliche Silberkonzentration täuscht einen Chloridgehalt unterhalb $120 \mathrm{mVal}$ vor. Diese Fehlerquelle läßt sich auf folgende Arten erkennen und beseitigen:

Man könnte daran denken, die Trübung als Kriterium für das Auftreten der oben genannten Komplikationen zu benutzen. Leider ist dieser qualitative Anhaltspunkt nicht eindeutig, da ja auch im Falle von stark lipoidhaltigen Seren Trübungen auftreten können. Prinzipiell könnte man auch daran denken, extrem pathologische Seren durch eine Tüpfelreaktion zu erkennen (13).

Neben diesen qualitativen Erkennungsmerkmalen gibt es aber zuverlässige flammenphotometrische Methoden, um Fehler bei extrem pathologischen Seren auszuschalten:

1. Liegen die Ablesungen nach der normalen Methode oberhalb $115 \mathrm{mVal}$, so besteht die Möglichkeit, daß die oben genannte Komplikation aufgetreten ist. Dann wird man zusätzlich eine Vorverdünnung vornehmen. Dieses Vorgehen hat den Vorteil, daß man nicht alle Seren vorverdünnen muß (siehe unten). Es hat aber den Nachteil, daß dieses einmal angeordnete Nachverdünnen aus Bequemlichkeit oder in Eile „vergessen" wird.

2. Man fertigt grundsätzlich von allen Serèn außer der normalen Probenvorbereitung eine zweite vorverdünnte Reihe an. Dies hat den Nachteil, daß der Arbeitsaufwand für das Erstellen der zweiten, vorverdünnten Reihe einen größeren Arbeitsaufwand bedeutet.

\section{Diskussion}

In der vorliegenden Arbeit wird gezeigt, daß man mit den beiden in Deutschland am weitesten verbreiteten Filterflammenphotometern den Serum-Chlorid-Gehalt bestimmen kann. Daß zwei verschiedene Methoden angegeben werden, hat zufällige Gründe. Es wurde nämlich an zwei Stellen unabhängig voneinander aber nach vorheriger Absprache das gleiche Ziel angesteuert. Möglicherweise läßt sich die eine Methode auf das andere Gerät übertragen und umgekehrt, was aber nicht.geprüft wurde. Ein Vergleich beider Methoden ergibt folgende Vor- und Nàchteile:

Die Vorschrift für das Eppendorf-Gerät hat den Vorzug, $\mathrm{da}$ man mit Pipetten ausschließlich aus dem Mikro- 
litersystem „Eppendorf“ auskommt. Weiterhin hat sie den Vorzug, daß der von ihr bestrichene Konzentrationsbereich größer ist. Als Nachteil ist zu erwähnen, $\mathrm{da} \beta$ der interessierende Konzentrationsbereich $(90$ bis $120 \mathrm{mVal}$ ) nicht soweit gespreizt ist wie bei der Methode am PF 5-Gerät, wo dieser Bereich die ganze Skala ein- nimmt. Weiterhin ist es aufgrund der etwas geringeren Nachverdünnung nicht so leicht, erforderlichenfalls zu noch kleineren Serum-Mengen überzugehen.

Für die technische Hilfe danken wir (BechtLer) Frl. Siebert u. Frl. Dahlmann in Hamburg.

\title{
Literatur
}

1. Lang, W., diese Z. 3, 186 (1965). - 2. Lang, W., Der optimale Arbeitsbereich indirekter flammenspektrophotometrischer Analysenverfahren mit vorausgehender Fällungsreaktion. Mikrochim. Acta (Wien), 462 (1966). - 3. Handbuch zum Flammenphotometer Eppendorf, Eppendorf Gerätẹbau, Hamburg (1962). 4. KaISER, H., Z. analyt. Chem. 209, 1 (1965). - 5. HerrmanN, R. und C. Th. J. Alkemade, (übersetzt von P. T. GilberT), Flame Photometry Interscience Publishers, New York (1963). - 6. Menis, O., H. P. House und C. T. Rains, Analytic. Chem. 29, 76 (1957). - 7. Linder, A., Statistische Methoden, 3. Aufl. Birk- häuser Verlag, Basel-Stuttgart (1960). - 8. LANG, K., Biochem. Z. 290, 289 (1937). - 9. Schales, O. und S. S. Schales, J. biol. Chemistry 140, 879 (1941). - 10. Rausch, L. und H. Graul, Ärztl. Wschr. 4, 591 (1949). - 11. Stamm, D., Tagesschwankungen der Konzentration diagnostisch wichtiger Blutbestandteile. Habilitat., Med. Fak. Gießen (1966). - 12. Holleman-Wiberg, Lehrb. d. anorganischen Chemie, 47.-56. Auf. Walter de Gruyter \& Co., Berlin (1960). - 13. Frigr, F., Tüpfelanalyse, Bd. I. Akademische Verlagsgesellschaft mbH. Frankfurt/Main (1960).

Professor Dr. R. Herrmann 63 Gießen, Gaff kystr. 14

\section{Schnellbestimmung des Alkoholgehaltes im Blut und in anderen Körperflüssigkeiten}

\author{
Von E. VIDIC 1 ) \\ Aus dem Institut für gerichtliche und soziale Medizin der Freien Universität Berlin
}

(Direktor: Prof. Dr. med. W. Krauland)

(Eingegangen am 18. Januar 1967)

Für klinisch-diagnostische Zwecke sowie für wissenschaftliche Untersuchungen wurde ein Schnellverfahren zur Bestimmung des Alkoholgehaltes in Blut und anderen Körperflüssigkeiten entwickelt. In der beschriebenen, leicht zu bedienenden Glasapparatur kann die Bestimmung ohne besondere Einarbeitung in 20 Min. vorgenommen werden. Das Verfahren beruht auf der Verdampfung der Flüssigkeit in einem Luftstrom und Absorption der Dämpfe in Vanadinschwefelsäure. Bei der photometrischen Auswertung der Reaktion wird eine ausreichende Genauigkeit - entsprechend einer einfachen Standardabweichung von $0,05-0,08 \%$ - exzielt.

A rapid method for the determination of alcohol in blood and other body fluids was developed for clinical-diagnostic and for scientific studies. In the described, easily available glass apparatus, the determination can be carried out in 20 minutes without previous experience. The method is based on evaporation of the liquid in an air stream and adsorption of the vapour in vanadol-sulphuric acid. Photometric measurement of the reaction product provides a sufficiently accurate determination, with a standard deviation of $0.05-0.08 \%$.

Berichte und Statistiken der Kranken- und Heilanstalten sowie unsere Erfahrungen zeigen, daß Unfälle unter Alkoholeinwirkung immer häufiger werden. KRAMER (1) berichtete z. B. aus den Städt. Krankenanstalten Dortmund, da $B$ jeder siebente Patient betrunken zur Behandlung kam und daß $63 \%$ der Kopfverletzten alkoholisiert waren. Die Beurteilung der Kopfverletzungen wird bei dem Vorliegen einer Alkoholisierung erschwert, da durch sie zerebrale Symptome überdeckt werden können. Umgekehrt kann dabei oft der Grad der Alkoholisierung nicht erkannt werden, wodurch für den Patienten Gefahren erwachsen können. Auch in anderen Fällen, insbesondere bei der Einlieferung von unter Gift- oder Medikamentenwirkung stehenden Patienten, müssen oft Eingriffe und therapeutische Maßnahmen ohne Kenntnis des Grades einer evtl. vorhandenen Alkoholisierung vorgenommen werden, was zu Folgen für den Patienten führen kann. Eine rasche Kenntnis des Blutalkoholgehaltes kann ebenso bei der Auffindung

\footnotetext{
1) Auszugsweise vorgetragen und vorgeführt bei der Tagung der Deutschen Gesellschaft für gerichtliche Medizin in Freiburg/Br. am 8. Oktober 1966.
}

betrunkener, hilfloser Personen notwendig sein, um Gefahren abzuwenden. Der Alkoholisierungsgrad spielt auch bei der Beurteilung der Ergebnisse von Leichenöffnungen häufig eine nicht unbedeutende Rolle, so daß seine Bestimmung während der Vornahme der Sektion wesentlich zur Stellung der Diagnose beizutragen vermag. Nicht zuletzt kann auch bei wissenschaftlichen Untersuchungen sowie bei Trinkversuchen zur Ermittlung der Alkoholabbaugeschwindigkeit und bei der Feststellung von psychischen und physischen Ausfallerscheinungen eine rasche Orientierung über den Blutalkoholspiegel von erheblichem Vorteil sein. Die genannten, noch unvollständigen Hinweise auf die Bedeutung, die einer raschen Alkoholbestimmung zukommt, lassen erkennen, daß im Rahmen anderer diagnostischer Untersuchungen zweifellos auch ein echter Bedarf nach einem mit möglichst einfachen Mitteln durchführbaren und jederzeit einsatzbereiten Schnellverfahren besteht.

Bei dem derzeitigen Stande der Untersuchungstechnik sind die Laboratorien, die sich mit der routinemäßigen Bestimmung des Blutalkoholgehaltes befassen nicht in 